\title{
Evaluation of Neurocognitive Dysfunction after Coronary Artery Bypass Surgery
}

\author{
Tawfiq Ahmed' ${ }^{1}$, Md. Rezaul Karim², Jahangir Haider Khan², Shahriar Moinuddin² \\ ${ }^{1}$ Department of Cardiac Surgery, Sir Salimullah Medical College, Dhaka, ${ }^{2}$ Department of \\ Cardiac Surgery, NICVD, Dhaka
}

\begin{abstract}
:
Keywords:

Neurocognitive

dysfunction,

Objective: The Neurological injury is an important complication after coronary artery bypass surgery $(C A B G)$. The incidence of neurocognitive impairment after cardiac surgery varies from $20 \%$ to $80 \%$. In this study we tried to analyze this difference of neurologic dysfunction between On-pump CABG and Off-pump $C A B G(O P C A B)$.

Ischaemic heart

disease,

Coronary artery

bypass surgery.

Methods:This is a case control study done in National Institute of Cardiovascular Disease (NICVD), Dhaka during the period of July 2012 to June 2014. Sixty Patients with Ischemic heart disease were the study population. Group- A includes 30 patients underwent on pump CABG, Group-B 30 patients underwent OPCAB. All the patients of both the groups were followed up to 2 month's postoperatively to find out any neurological and neurocognitive dysfunctionby observing motor function, sensory function, Mini Mantel state (MMS) Examination, orientation, memory, attention and calculation, recall and language test.

Results: Neurocognitive dysfunction in the early postoperative period is significantly different among the groups. Neurocognitive dysfunction was more in Group A in comparison to Group B, On 3rd and 8th POD the MINI Mental Scores were found to be significantly lower in On-pump group than those in Off-pump group $(22.0 \pm 5.28$ vs. $25.67 \pm 3.34, p=0.002$ and $25.93 \pm 3.11$ vs. $26.63 \pm 2.50, p=0.023$ respectively). This neurocognitive dysfunction gradually improved by the end of two month postoperative period. Only $6.66 \%$ patient in Group-A was found neurocognitically dysfunctional and was referred to neurophysician for further treatment. In case of OPCAB Group, no patient suffered fromneuorocognitive dysfunction.
\end{abstract}

Conclusion: This study has convincingly shown cardio-pulmonary bypass (CPB) has had detrimental effect on neurocognitive function in patients who underwent $C A B G$.

(Cardiovasc. j. 2018; 10(2): 186-193)

\section{Introduction:}

The Neurological injury is an important complication after CABG. There is considerable evidence that early postoperative cognitive dysfunction is related to a combination of three factors often associated with CPB: (micro) embolism, hypoperfusion, and the systemic inflammatory response. Intraoperative formation of gaseous emboli and aggregated platelets, atherosclerotic debris, hypoperfusion, hypotension, hyperthermia, hyperglycaemia, surgical trauma, blood loss, Anaesthetic agents, arrhythmia and transfusion all enhance the risk of cognitive dysfunction.

There are two types of Neurological injury, TypeI includes stroke, transient ischemic attack and coma and the incidence is approximately 3 to 6 percent. Type-II injury is more subtle and includes impairment of cognitive functions. These defects associated with attention, concentration, short term memory, fine motor function and speed of the mental response. The incidence of neurocognitive impairment after cardiac surgery varies from $20 \%$ to $80 \% .{ }^{1}$ Based on prospective studies, however it is apparent that the incidence of subtle postoperative neurologic and neuropsychological abnormalities is much higher, closer to 50 percent in the first week after cardiac surgery. ${ }^{2}$ These apparent high rate of subtle neurologic impairment detected prospectively are in sharp contrast to the considerably lower incidence of stroke after cardiac surgery, reported as 1-5 percent, in several large retrospective series from different centers. ${ }^{3}$ There are several reasons for these apparent differences in the reported incidences the timing, thoroughness and the reproducibility of the neurologic examinations, as well as the incorporation of the preoperative assessment for comparison, all determine the sensitivity and

Address of Correspondence: Dr. Tawfiq Ahmed, Department of Cardiac Surgery, Sir Salimullah Medical College, Dhaka, Bangladesh. Email: tawfiq.ahmed@yahoo.com 
accuracy with which postoperative neurologic dysfunction can be detected. Most importantly, many of the earlier studies were based on a retrospective chart review, which only detected the most clinically obvious neurologic dysfunction syndromes as was elegantly demonstrated by Sotaniemi and his colleagues. ${ }^{4}$ In a study of 100 patients in whom a 37 percent incidence of neurologic dysfunction had been diagnosed by careful neurologic examination, the prevalence of cerebral abnormalities detected by retrospective analysis of the same patient pool was only 4 percent. ${ }^{5}$ The incompleteness of the records, a reluctance to document apparently minor complication and most importantly insensitivity to subtle neurologic dysfunction are being the main reason for there apparent disparities. Many of the type of impairment now being investigated are sub-clinical and are not readily detectable by a standard "foot of the bed" assessment. The fact that many of these abnormalities are apparently transient also contributes to the tendencies to minimize their clinical relevance. It is now established that such reproducible and quantifiable dysfunction is an objective outcome measure and can at least act as a benchmark.

Vast literature on the risk factors of neurobehavioral disorders after cardiac surgery indicates that postoperative decreased of neurological function seems to be associated with advanced age lower preoperative cognitive performance, higher degree of proximal atherosclerosis and length of clump or perfusion time. ${ }^{6,7,8}$

\section{Methods:}

This cross-sectional study was performed in the Department of Cardiovascular Surgery, National Institute of Cardiovascular Disease (NICVD), Sher-E-Bangla Nagar, Dhaka, Bangladesh from July 2012 to June 2014. The study was carried out on patients with ischemic heart disease who underwent CABG. Total number of Patient was sixty, thirty in each group. Data were analyzed by statistical program for Social Science (SPSS). All patients with Ischemic heart disease underwent Coronary artery bypass graft surgery with or without cardiopulmonary bypass were included. Exclusion criteriawere Patient associated with cerebro-vascular disease, neurological and psychological abnormality, hepatic and renal insufficiency, patient who underwent any emergency cardiac surgery, redo cardiac surgery, valve surgery and congenital surgery.

Each group included thirty patients. Group - A: On pump CABG, Group-B OPCAB.In both the groups the risk factors, such as diabetes mellitus, hypertension, smoking and hyperlipidemia were recorded and compared. A standard 12 lead ECG were taken in all cases pre-operatively and postoperatively and was examined for rate, rhythm, axis deviation, chamber enlargement and evidence of ischemia. Pre-operative Q-wave were recorded in all the patients of both the groupsand compared. Echocardiography was performed pre-operatively in both the groups to assess the functional status of the myocardium. Ejection fraction were recorded and competed among the groups. Coronary angiogram (CAG) was evaluated in all patients in both groups to find out the site to lesion percentage of luminal stenosis, distal flow of dye and assessment of graftable site and the number of diseased vessels. Only double and triple vessel diseases were included in the study. Neurological examination was done in both the groups pre-operatively and post-operatively for assessment. Muscle power, Muscle tone and reflexes were recorded for motor function and pain and touch sensation was recorded for sensory function. Mini Mantel state (MMS) Examination was done in both the groups pre-operatively and post-operatively and at the time of discharge and follow up. The MiniMental State Examination (MMSE) or Folstein test is a 30-point questionnaire that is used extensively in clinical and research settings to measure cognitive impairment. Any score greater than or equal to 24 points (out of 30) indicates a normal cognition. Below this, scores can indicate severe (d"9 points), moderate (1018 points) or mild (19-23 points) cognitive impairment. 9,10

Orientation, antegrade memory, attention and calculation, recall and language test were done. And the score were compared in both the groups. ACCT (Aortic crossclamp time), ECCT (Extracorporeal circulatory time) and total operation time were recorded in on-pump group 
per-operatively to see the distributionin the group. All the patients of both the groups were followed up to 2 month's postoperatively to find out any neurological and neurocognitive dysfunction and were consulted with neurophysician for further management, if needed.

\section{Results:}

This study was carried out in the Department of Cardiovascular Surgery, NICVD. The results and observations of the study are being presented as follows: There were 60 patients. The Sixty (60) percent of the patients in Onpump group and $53.3 \%$ in Off-pump group were between $50-60$ years of age. Nearly one-quarter (23.3\%) of the patients in each group were between $40-50$ years of age. Very few patients in each group were below 40 years of age or of 60 years and above. No significant variation was observed between groups in terms of age (50.17 \pm 8.31 vs. $49.23 \pm 7.99$ years, $p=.659)$. It was found that there is also no significant difference between two groups. The groups were almost homogeneous in terms of sex as well $(p=0.306)$. Risk factors considering in both groups $\mathrm{A}$ and Group-B patients are hypertension, diabetes, smoking, hyperlipidemia and old MI, more than $50 \%$ of the patients in both groups were diabetic, hypertensive and hyperlipidemic and more the $60 \%$ patients of both groups had old MI. Less than $40 \%$ of both groups were smoker. So there was no significant difference in the presence of risk factor among the groups.

In pre-operative echocardiographic study left ventricular ejection fraction were studied in all patients. LVEF was divided into two groups. One was more than $50 \%$ and other was less than $50 \%$. In group A more than $18(60 \%)$ of the patient had LVEF $<50 \%$ and 12 (40\%) had LVEF $<50$. In Group-B 14 (46.6\%) patient had LVEF $>50 \%$ of $16(54.4 \%)$ patient had LVEF > 50. But there was no significant difference in LVEF among the groups(Table-I).

Coronary angiogram of all the 60 patients in both group revealed significant stenosis of double vessel in 4 (13.3\%) patients, triple vessel stenosis in 26 and left main in 7 patients in group $\mathrm{A}$ and double vessel disease in 10 (33.3\%) patients triple vessels disease in 20 patients and left main disease in 3 in group B(Table-II).

In On-pump group nearly half $46.6 \%$ of the patients needed 3 grafts followed by $26.7 \%$ patients 2 grafts and the rest $26.7 \%$ cases 4 grafts, where as in Off-pump group $56.6 \%$ of the cases required 3 grafts, 30\% cases 2 grafts and $13.3 \%$ cases 4 grafts. The groups were found to be homogenous with respect to number of grafts needed $(p=0.055)$ (Table-III).

In group A, Two-third (60\%) of the cases had their aorta cross-clamped for 60 minutes or more, while the rest one-third (40\%) for less than

Table-I

Echo cardiographic findings of the study population.

\begin{tabular}{lcccccc}
\hline Findings & \multicolumn{2}{c}{ Group-A } & & \multicolumn{2}{c}{ Group-B } & p-value \\
\cline { 2 - 3 } & No & & & No & $\%$ & \\
\hline LVEF $>50 \%$ & 18 & $60 \%$ & & 14 & $46.6 \%$ & 0.46 \\
LVEF $<50 \%$ & 12 & $40 \%$ & & 16 & $54.4 \%$ & 0.52 \\
\hline
\end{tabular}

Table-II

Coronary artery lesions of the study population.

\begin{tabular}{lccccc}
\hline Vessel Involved $>75 \%$ & \multicolumn{2}{c}{ Group-A } & & \multicolumn{2}{c}{ Group-B } \\
\cline { 2 - 3 } \cline { 5 - 6 } stenosis & No & $\%$ & & No & $\%$ \\
\hline 2 vessel & 4 & $13.3 \%$ & & 10 & $33.3 \%$ \\
3 vessel & 26 & 86.6 & & 20 & $66.6 \%$ \\
Left main & 7 & $23.1 \%$ & & 3 & $10 \%$ \\
\hline
\end{tabular}


Table-III

Comparison of number of grafts in the study population.

\begin{tabular}{ccccccc}
\hline No. of graftsGiven & \multicolumn{2}{c}{ Group-A } & & \multicolumn{2}{c}{ Group-B } & p-value \\
\cline { 2 - 3 } \cline { 5 - 6 } & No & $\%$ & & No & $\%$ & 0.055 \\
\hline 2 & 8 & $26.6 \%$ & & 9 & $30 \%$ & \\
3 & 14 & $46.6 \%$ & & 17 & $56.6 \%$ & \\
4 & 8 & $26.6 \%$ & & 4 & $13.3 \%$ & \\
\hline
\end{tabular}

60 minutes during operation. The mean ACCT was 67.54 minutes and the lowest and highest ACCT were observed to be 51 and 107 minutes respectively. $66.7 \%$ of the cases had ECCT less than 100 minutes and the rest $33.3 \% 100$ minutes or more. The mean ECCT was 95.6 minutes and the minimum and maximum ECCT were 84 and 202 minutes respectively.

Total operation time-Comparison of the outcome shows total operation time was $352.67 \pm 50.61$ minutes in group A and $311.47 \pm 44.86$ minutes in group B. There is significant difference between two groups (Table-IV).

The ventilation time, postoperative ICU stay and hospital stay was significantly higher in the Group A than those in Group B (19.4 3.12 vs. $8.23 \pm 2.92$ hours, $p<0.001 ; 4.93 \pm 1.01$ vs. $4.03 \pm$ 0.62 days, $p<0.001$ and $11.27 \pm 1.55$ vs. $9.73 \pm$ 1.89 days, $\mathrm{p}=0.001$ respectively) (Table-V).

The Group-B demonstrated a significantly better outcome in muscle tone and strength (13.3\%) compared to Group-A counterpart (40\%) ( $\mathrm{p}<$ 0.05).Reflexes were sluggish in $33.3 \%$ in group $A$ and $16.7 \%$ in group B and difference was insignificant (Table-VI).
The early sensory function test demonstrated 100\% normal outcome in Group A, while Group B had somewhat less normal outcome (93.3\%). The groups were not found to be significantly different in terms of early sensory functions ( $p$ $>0.05$ ) (Table-VII).

Table VIII compares the late neurological assessment between groups. All the neurological functions like motor, sensory and reflexes were found $100 \%$ intact in both the groups.

Table IX demonstrates the comparison of postoperative neurocognitive function using MINI Mental Score. On $3^{\text {rd }}$ and $8^{\text {th }}$ POD the MINI Mental Scores were found to be significantly lower in On-pump group than those in Off-pump group $(22.0 \pm 5.28$ vs. $25.67 \pm 3.34$, p $=0.002$ and $25.93 \pm 3.11$ vs. $26.63 \pm 2.50, \mathrm{p}=$ 0.023 respectively) suggesting that return of cognitive function following $\mathrm{CABG}$ in the OPCAB group is achieved much earlier than On pump group.By the end of the study period after (2 month) most of the patients had normal recovery. Only 2 patients in Group A had dysfunctional cognitive scores.

\section{Table-IV}

Comparison of total operation time in both groups.

\begin{tabular}{lcc}
\hline Group-A & Group-B & p-value \\
\hline $352.67 \pm 50.61$ & $311.47 \pm 44.86$ & 0.0015 \\
\hline
\end{tabular}

Data were analyzed using Student's t- Test and the difference was significant.

Table-V

Comparison of outcome between groups.

\begin{tabular}{lccc}
\hline Outcome & \multicolumn{2}{c}{ Group } & p-value \\
\cline { 2 - 3 } & On-pump & Off-pump & \\
\hline Post Operative Ventilation time (hours) & $19.40 \pm 3.12$ & $8.23 \pm 2.92$ & $<0.001$ \\
Post Operative ICU stay (days) & $4.93 \pm 1.01$ & $4.03 \pm 0.62$ & $<0.001$ \\
Post Operative Hospital stay (days) & $11.27 \pm 1.55$ & $9.73 \pm 1.89$ & 0.001 \\
\hline
\end{tabular}

Data were analysed using Student's t-Test and presented as mean \pm SD; level of significance was 0.05. 
Table-VI

Comparison of motor function impairment between the groups.

\begin{tabular}{lcccccc}
\hline Motor functionimpairment & \multicolumn{2}{c}{ Group-A $(\mathrm{n}=30)$} & & \multicolumn{2}{c}{ Group-B $(\mathrm{n}=30)$} & p-value \\
\cline { 2 - 3 } & No & & & No & $\%$ & \\
\hline Tone and strength & 12 & $40 \%$ & & 4 & $13.3 \%$ & 0.02 \\
Reflexes & 10 & $33.3 \%$ & & 5 & $16.7 \%$ & 0.136 \\
\hline
\end{tabular}

Data were analyzed by Chi-Square test with Yates correction.

Table-VII

Comparison of early sensory function impairment between the groups.

\begin{tabular}{lcccccc}
\hline Sensory functionimpairment & \multicolumn{2}{l}{ Group-A $(\mathrm{n}=30)$} & & \multicolumn{2}{c}{ Group-B $(\mathrm{n}=30)$} & p-value \\
\cline { 2 - 3 } & No & & & No & $\%$ & \\
\hline Pain and touch & 2 & $6.7 \%$ & & 0 & $0 \%$ & 0.246 \\
\hline
\end{tabular}

Data were analyzed by Chi-Square test with Yates correction.

\section{Table-VIII}

Neurocognitive function between the groups on $3^{\text {rd }}$ post operative day, $8^{\text {th }}$ post operative day and 2 months after operation.

\begin{tabular}{|c|c|c|c|c|c|}
\hline \multirow[t]{2}{*}{ NeurocognitiveImpairment } & \multicolumn{2}{|c|}{ Group-A $(n=30)$} & \multicolumn{2}{|c|}{ Group-B $(\mathrm{n}=30)$} & \multirow[t]{2}{*}{ p-value } \\
\hline & No & $\%$ & No & $\%$ & \\
\hline \multicolumn{6}{|l|}{$\overline{3^{\text {rd }} \text { post operative day }}$} \\
\hline Orientation & 8 & $26.6 \%$ & 4 & $13.3 \%$ & 0.55 \\
\hline Antegrade memory & 4 & $13.3 \%$ & 2 & $6.6 \%$ & 0.60 \\
\hline Attention & 24 & $72 \%$ & 12 & $40 \%$ & 0.05 \\
\hline Recall & 16 & $53.3 \%$ & 10 & $33.3 \%$ & 0.05 \\
\hline Language & 11 & $36.6 \%$ & 5 & $16.6 \%$ & 0.045 \\
\hline \multicolumn{6}{|l|}{$8^{\text {th }}$ post operative day } \\
\hline Orientiation & 5 & $16.6 \%$ & 4 & $13.3 \%$ & 0.689 \\
\hline Antegrade memory & 2 & $6.6 \%$ & 0 & $0 \%$ & 0.5 \\
\hline Attention & 18 & $60 \%$ & 10 & $33.3 \%$ & 0.0549 \\
\hline Recall & 13 & $43.3 \%$ & 8 & $26.6 \%$ & 0.47 \\
\hline Language & 7 & $23.3 \%$ & 2 & $6.6 \%$ & 0.49 \\
\hline \multicolumn{6}{|l|}{2 months after operation } \\
\hline Orientiation & 0 & $0 \%$ & 0 & $0 \%$ & \\
\hline Antegrade memory & 0 & $0 \%$ & 0 & $0 \%$ & \\
\hline Attention & 6 & $20 \%$ & 0 & $0 \%$ & 0.4 \\
\hline Recall & 4 & $13.3 \%$ & 0 & $0 \%$ & \\
\hline Language & 0 & $0 \%$ & 0 & $0 \%$ & \\
\hline
\end{tabular}

Data were analyzed by Chi-Square test with Yates correction.

Table-IX

Comparison of neurocognitive function between the groups

\begin{tabular}{lccc}
\hline Time of evaluation & \multicolumn{2}{c}{ Mini mental score (Mean +_SD) } & p-value \\
\cline { 2 - 3 } & On-pump $(\mathrm{n}=30)$ & Off-pump $(\mathrm{n}=30)$ & \\
\hline $3^{\text {rd }}$ POD & $22.00+\_5.28$ & $25.67+\_3.34$ & 0.002 \\
$8^{\text {th }}$ POD & $25.93+\_3.11$ & $27.63+\_2.50$ & 0.023 \\
$2^{\text {nd }}$ month POP & $28.63+\_1.94$ & $29.30+\_0.99$ & 0.101 \\
\hline
\end{tabular}

Data were analyzed with help of Student's t-Test. 


\section{Discussion:}

This study was performed in NICVD, Dhaka. Included 60 patients of them 56 were male and only (four) were female. Total male female ratio being $93.3 \%$ male and only $6.7 \%$ female. The patients were divided into two groups. Group A includes CABG (on pump) and Group B includes OPCAB. There was slightly higher percentage of female in Group A (10\%) than in Group B (3.3\%).

In Group-A the age ranged from 32 to 70 years with a mean $\pm \mathrm{SD}$ of $50.166 \pm 8.31$ years. The majority of the patients are in the age group of 50-60 years. In Group-B the age ranged from 32 to 67 years with a mean $\pm \mathrm{SD}$ of $49.23 \pm 7.99$ years, majority of the patients are in the age range of 50 to 60 years. So there is no significant difference in age among the groups. But there is a definite male predominance in both the groups as the incidence of coronary artery disease is higher in male.Risk factors considering in both groups A and Group-B patients are hypertension, diabetes, smoking, hyperlipidemia and old MI, more than $50 \%$ of the patients in both groups were diabetic, hypertensive and hyperlipidemia and more the $60 \%$ patients of both groups had old MI. Less than $40 \%$ of both groups were smoker. So there was no significant difference in the presence of risk factor among the groups. These findings were similar with the study done by Slogoff and his colleagues. ${ }^{16}$

In pre-operative echo cardiographic study left ventricular ejection fraction were studied in all patients. LVEF was divided into two groups. One was more than $50 \%$ and other was less than $50 \%$. In group A more than $18(60 \%)$ of the patient had LVEF $<50 \%$ and $12(40 \%)$ had LVEF $<50$. In Group-B $14(46.6 \%)$ patient had LVEF $>50 \%$ of $16(54.4 \%)$ patient had LVEF > 50. But there was no significant difference in LVEF among the groups.This findings were similar with the study done by Gorlitzer and his colleagues. ${ }^{16}$

The development of coronary angiography by Manson Sones and Shirey was the Landmark achievement that permitted precise definition of the anatomic obstruction and laid the foundation for coronary artery by pass surgery. ${ }^{13}$ Coronary angiogram of all the 60 patients revealed significant stenosis of double vessel-4
(13.3\%) patents, triple vessel in $26(86.6 \%)$ patents and left main in 7 (23.1\%) patients in Group-A and in Group-B, double vessel 10 (33.3\%) patents, Triple vessel 20 (66.6\%) patients and left main $3(10 \%)$ were present. All the stenosis vessels were graft table.

The number of grafts need in both the groups were for on pump group nearly half 14 (46.6\%) of patients required 3 grafts, $8(26.6 \%)$ patients required 4 grafts and $8(26.6 \%)$ patients required 2 grafts, where as in off pump group-17 (56.7\%) patients needed 3 grafts, 9 (30\%) patients needed 2 grafts and 4 (13.3\%) patient needed 4 grafts. So the groups were found to be homogenous with respect to the number of graft required. So there is no significant difference among the groups. The Aortic Cross clump time (ACCT) and extra corporeal Circulation time (ECCT) was recorded only for on pump group. So only the distribution of patients were studied in the group. With respect to ACCT patient were divided in two groups. Patient ACCT required more than 60 minutes and less than 60 minutes. 18 (60\%) patients required 60 minutes or more while 12 (40\%) patient needed less than 60 minutes. The range was 51 minutes to 107 minutes mean was 67.54 minutes with respect of ECCT 20 (66.7\%) patient need less than 100 minutes and rest 10 $(33.3 \%)$ required more than 100 minutes range was 84 to 202 minutes with mean of 95.6 minutes. These findings were similar with the study done by Kalterand his colleagues. ${ }^{5}$

Total operation time in Group A and Group B was studied and compared among the groups and there was difference in the total operation time. $352.67 \pm 60.61$ minutes in Group A and $311.47 \pm 44.86$ minutes in Group B were recorded, which was significant. The post operative ventilation time (hour) ICU stay (days) and total post operative hospital stay (days) were studied and compared among the groups. All of them shows significantly higher in the On pump group than those in off pump $(19.4 \pm 3.12$ VS $8.23 \pm$ 2.92 hours, $4.93 \pm 1.01$ VS $4.03 \pm 0.62$ days, 11.27 \pm 1.55 VS $9.73 \pm 1.89$ days, respectively). This findings were similar with the study done by Gorlitzer and his colleagues. ${ }^{16}$

Neurophysiological and neuro cognitive function were assessed prior to intended operative 
procedure. Neurophysiological and neuropsychometric tests were done and a base line was set. Patients with abnormal neurological or neuropsychometric function were excluded from the study.

The incidence of post operative cerebral complications following coronary artery bypass surgery widely depends on the study design, methods and criteria used to assess neurologic injury and timing of follow up examination, type of cardiac surgical procedure. ${ }^{15}$

The incidents of cerebral dysfunction after cardiac surgery with $\mathrm{CPB}$ varied over a wide range from 4 to $70 \%$. These variability is due to several difference in CPB, surgical and anesthetic technique. ${ }^{14}$ In a study of 100 patient in whom a $37 \%$ incidents of neurologic dysfunction had been diagnosed by a careful neurological examination by Kalterand his colleagues. ${ }^{5}$ In a study done by Diedderik and his colleagues, there was some substantial neurocognitive dysfunction after cardio pulmonary bypass surgery in the early post-operative period which was less marked in off-pump procedure. ${ }^{11}$ Study done by Gorlitzer and his colleagues found that cognitive brain dysfunction is an significant adverse event related to on-pump coronary artery bypass surgery (20\% to $80 \%)$ which may affect length of hospital stay, quality of life, the rehabilitation process and work performance. ${ }^{12}$

Post operative neurophysiological functions are divided into motor and sensory function. Motor function is assessed by muscle tone, strength and reflexes. Sensory function is tested by pain and touch sensation. They were grouped in early includes $3^{\text {rd }}$ and $8^{\text {th }}$ post operative and late that is after 2 month.

In the early motor function test the off pump group demonstrated a significantly better outcome in muscle tone and strength (13.3\%) compared to on pump (40\%). Reflexes were sluggish in (33.3\%) in Group A and (16.3\%) in Group B and difference was non-significant.

In early sensory function test demonstrated $100 \%$ normal outcome in off pump group, while the on pump group had somewhat less normal outcome (93.3\%). The groups were not found to be significantly different in terms of early sensory function.
The neurologic dysfunction after CPB range from $1 \%$ to $9 \%$ of stroke, $3 \%$ to $4 \%$ alter mental status and $24 \%$ to $40 \%$ of neuropshycometric deficits. ${ }^{17}$

In late neurophysiological assessment between the groups all the functions like motor, sensory and reflexes were found $100 \%$ intact. Neurocognitive function between the groups demonstrates the comparison of postoperative neurocognitive function using Mini Mental Score Examination on $3^{\text {rd }}, 8^{\text {th }}$ post operative day and after 2 months post operatively. On $3^{\text {rd }}$ and $8^{\text {th }}$ post operative days Mini Mental Score were found to be significantly lower in on pump groups than those in off pump group ( $22.0 \pm 5.28$ vs 25.67 \pm 3.34 and $25.93 \pm 3.11$ vs $26.63 \pm 2.50$ respectively). After $2^{\text {nd }}$ month post operative period Mini Mental Score Examination shows much improved in cognitive function in both groups. $28.63 \pm 1.94$ in on pump groups and 29.30 \pm 0.99 (almost nil) in off pump group.

From the study we found that on the $3^{\text {rd }}$ and $8{ }^{\text {th }}$ post operative days the neurocognitive dysfunction occurred in both the groups but significantly higher in on pump then OPCAB group. After 2 month only $6.6 \%$ patients were found dysfunctional in on pump group where as none was found dysfunctional in OPCAB group.

In a study done by Dijk and his colleagues there was some early neuropsychometric dysfunction found in both on pump and off pump groups which was significant. But in the late cognitive function there was no impairment in both the groups which is more or less similar to my study results. ${ }^{11}$

By the end of the study period after (2 month) most of the patients had normal recovery. Only 2 patients in Group A had dysfunctional cognitive scores. This (6.6\%) dysfunction result is similar to that of Slogoffand his colleagues. ${ }^{16}$ There is considerable evidence that early postoperative cognitive dysfunction is related to a combination of three factors often associated with CPB: (micro)embolism, hypoperfusion, and the systemic inflammatory response. Intraoperative formation of gaseous emboli and aggregated platelets, atherosclerotic debris, hypoperfusion, hypotension, hyperthermia, hyperglycaemia, surgical trauma, blood loss, and transfusion all enhance the risk of cognitive 
dysfunction. The majority of these causative factors, however, may occur independently of CPB for different reasons.

A much larger study focusing on these will help to determine the statistical significance of these observations.

\section{Conclusion:}

This study has convincingly shown cardiopulmonary bypass had detrimental effect on neurological function. There is a higher incidence of neurocognitive dysfunction in on pump CABG than OPCAB. Neuropsychometric abnormalities often remain unrecognized. This study helped in establishing the extent of the problem which can be minimized.

\section{Conflict of Interest - None.}

\section{References:}

1. Zamvar V, Khan NU, Madhavan A, Kulatilake N, Butchart EG. Clinical outcomes in coronary artery bypass graft surgery: comparison of off-pump and on-pump techniques. Heart Surgery Forum 2000; 5(2): 109-113.

2. Heyer EJ, Adams DC. Neurological assessment and cardiac surgery. J Cardiothorac Vasc Anesth 1996; 10: 99-104.

3. Murkin JM, Jeffery S. Central nervous system dysfunction after Cardiopulmonary bypass. In: Joel A Kaplan. Ed. Cardiac anesthesia. $3^{\text {rd }}$ edition, Philadelphia: WB Saunders 1993: 1225-1238.

4. Sotaniemi KA. Mononen H, Hokkannen TE. Long term cerebral outcome after open-heart surgery. Stroke 1986; 17: 410-416.

5. Kalter RD, Saum CM, Westein L. Cardiopulmonary bypass-associated hemostatic abnormalities. J Thorac Cardiovasc Surg 1979; 77: 427.

6. HofsteA WJ, Linssen CAM, Boezeman EHJF, Hengeveld JS, Leusink JA et al. Delirium and cognitive disorders after cardiac operations: relationship to pre and intraoperative quantitative electroencephalogram. Int $J$ Clin Monit Comput 1997; 14: 6-29.

7. Westaby S, Saatvedt S, White S, Katsumata T, van Oevern $\mathrm{W}$ et al. Is there a relationship between s-100 protein and neuropsychologic dysfunction after cardiopulmonary bypass? J Thorac Cardiovasc Surg 2000; 119: 132-137.

8. Roach G, Kanchuger M, Mangano C. Adverse cerebral outcome after coronary artery bypass surgery. Multicenter study of Perioperative Ischemia Research Group and the Ischemia Reaserch and Education Foundation Investigators. N Engl J Med 1996; 335: 1857-1863.

9. Pangman VC, Sloan J,Guse L. An Examination of Psychometric Properties of the Mini-Mental Status Examination and the Standardized Mini-Mental Status Examination: Implications for Clinical Practice. Applied Nursing Research 2000; 13 (4): 209-213.

10. Mungas D. In-office mental status testing: a practical guide. Geriatrics 1991; 46 (7): 54-58.

11. Dijk DV, Keizer AMA, Diephais JC, Durand C. Neurocognitive dysfunction after coronary artery bypass surgery. J Thorac Cordiovasc Surgery 2000; 120: 629-632.

12. Gorlitzer M, Kilo J, Czerny M, Zimpfer D, Baumer H, et al. Cardiopulmonary bypass affects cognitive brain function after coronary artery bypass graft. Ann Thorac Surg 2001; 72: 1926-1932.

13. Sones FM, Shirey EK. Cine Coronary arteriography. Mod Concepts Cardiovascular Disease 1962; 31: 735.

14. Padaychee TS, Parsons S, Theobold R. The effect of arterial filtration on reduction of gaseous microemboli in the middle cerebral artery during cardiopulmonary bypass. Ann Thorac Surg 1988; 45: 647-649.

15. Schell RM, Kem FH, Greely W. Cerebral Blood flow and metabolism during cardiopulmonary bypass. Anesth Analg 1993; 76: 849-865.

16. Slogoff S, Girgis KZ, Keats AZ. Etiologic factors in neuropsychiatric complication associated with cardiopulmonary bypass. Anesth Analg 1982; 61: 903-911.

17. Dijk D, Moons KGM, Keizer AMA, Janson EWL, Hijman $\mathrm{R}$, et al. Association between early and three month cognitive outcome after off-pump and on-pump coronary bypass surgery. Heart 2004; 90: 131-134. 